\title{
Most SA sunblock products 'can't take the heat', tests show
}

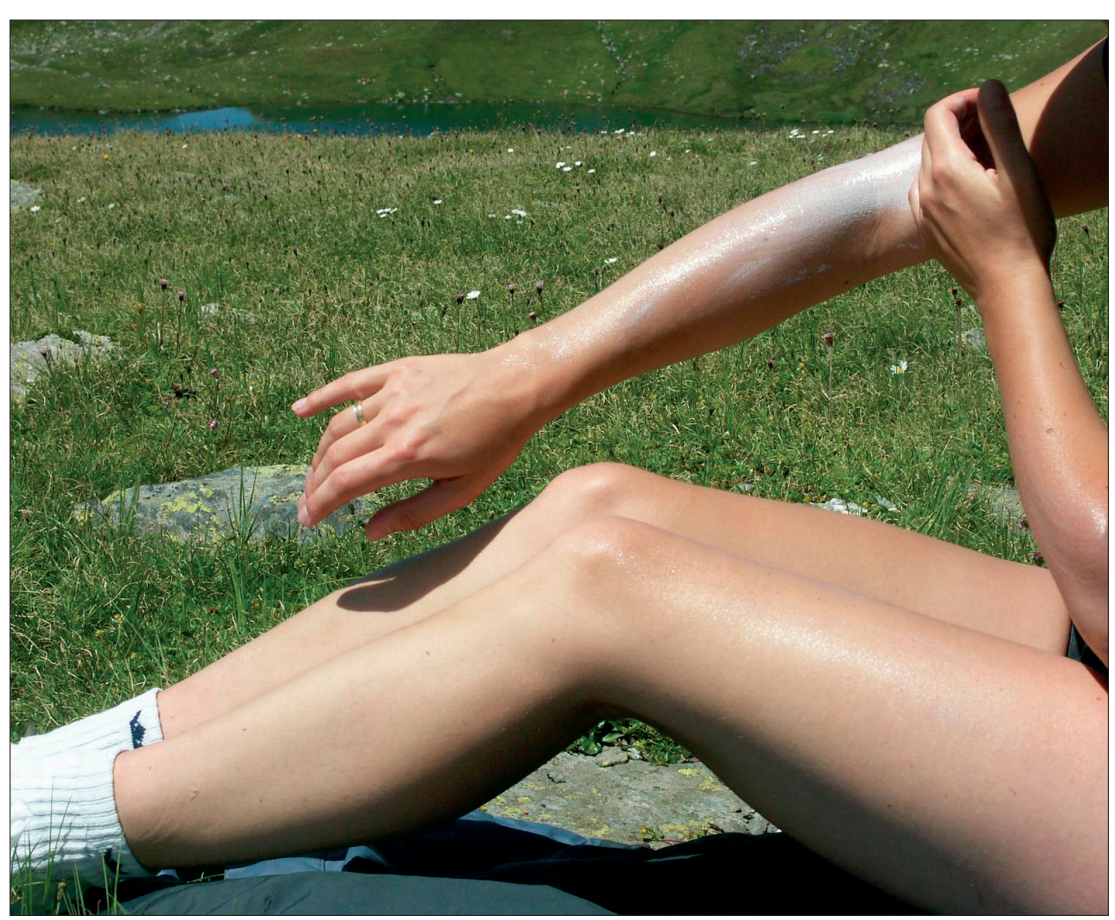

South African sunscreen manufacturers are hastily reformulating their products following confidential tests commissioned by the National Cancer Association of South Africa (CANSA) which show that most offer sub-optimal protection. This means that outdoor lovers (especially those in the Western Cape, where the incidence of malignant melanoma has trebled over the past 20 years), will face at least another summer using mostly below-par sunblock creams. Those who don't know that most locally sold creams don't offer decent protection beyond two hours of exposure to sunlight, will remain vulnerable.

In a story broken by the investigative weekly Noseweek this August, Cansa confirmed having asked a local company, Future Cosmetics, to test a $10 \%$ sample of the 357 individual sunscreen products sold locally (which included the three brand leaders) last September (2011). The sample came up well short of the optimal current internationally recommended (gold standard) protection. The not-for-profit NGO was anxious to see how the locally sold products fared when measured against the latest European Union (EU) standard, given the rise in malignant melanoma which is responsible for a full five per cent of all cancer deaths in South Africa.
About a decade ago it was discovered that UVA rays, in conjunction with UVB rays, were far more harmful than originally thought. UVA is still legally permitted in tanning salons using tanning beds across the country - in apparent complete ignorance of the latest research.

Those who don't know that most locally sold creams don't offer decent protection beyond two hours of exposure to sunlight, will remain vulnerable.

The now five-year-old EU standard is centered on the improved 'Colipa' test and measures the breakdown of the sunscreen over time under irradiation. Some local products require the UVA protection of the product to be at least one-third of its claimed sun protection (UVB) value (aka 'broad- spectrum protection'), but still break down after two hours or irradiation. Of those products 'Colipa tested' locally, one provided no protection after two hours of irradiation, and all broke down to some degree. In sharp contrast, sunscreens in EU countries have to provide much longerlasting and (better) UVA co-protection.

\section{Meet deadline or we withdraw endorsement - Cansa}

The Pretoria-based laboratory, Future Cosmetics (whose clients include the leading local sunscreen brand trio), insisted that Cansa sign a contract that its test results remain confidential. This prevented Cansa from going public and forced it to privately approach manufacturers on an individual basis, proposing a March 2013 deadline to re-formulate their products - or have Cansa withdraw its sales-boosting endorsement (printed on the labelling). The South African sunblock standard (SANS 1557: 2009) is considered insufficient, being based on what is known as the 'Boots standard'. Boots is a European cosmetic scientist who developed the eponymous test, originally adopted by most companies marketing such products.

The Boots-rated one-star products have the lowest ratio of UVA-to-UVB protection and five-star, the highest. The difference between the 'old' Boots test and the latest Colipa test is the irradiation requirement to indicate the levels of UVA protection and the cream's overall stability.There is also no local law enforcing compliance to any standard and it is left to the Cosmetics, Toiletries and Fragrances Association (CTFA) to selfregulate (its board is dominated by industry players).

When it was put (by Noseweek) to Heibrie le Roux, CEO of Future Cosmetics, that by withholding the information from the public, her company was potentially putting scores of lives at risk, she snapped: 'I don't have to talk to you!' Once the full potential impact was sketched for her as follows: 'For the next summer, perhaps two, people are going to be buying and using sunscreens on their children at the beach, at school sports events, confident they are providing the necessary protection. You know better, but won't tell them?', she added the following:'That's how we do business with all our customers. It would not be ethical of me to give you any information about our research; you are not our customer. She then terminated the call.

\section{Commercial conundrum}

Izindaba subsequently learnt that Le Roux's company spent a quarter of a million rand on the testing and risked closing its doors for business had she 'blown the whistle' on her clients. This arguably shifts the 
ethical onus for disclosure (and adjustment to the improved five-year-old scientific standard) strongly towards local sunblock manufacturers and distributors.

Sunscreens produced by Creighton Products at its factory in New Germany, KwaZulu-Natal, feature large on the confidential list of products found wanting in the tests commissioned by Cansa. In addition to manufacturing products under its own brand name, Island Tribe, the company supplies house-branded products specially packaged for various major chain stores including Spar, Clicks, DisChem, Pick n Pay and Mr Price. Creighton's website boasts that each of these house brands achieved a 10\% market share in their respective stores in the first year of trading.

\section{Of those products 'Colipa} tested' locally, one provided no protection after two hours of irradiation, and all broke down to some degree. In sharp contrast, sunscreens in EU countries have to provide much longer-lasting and (better) UVA co-protection.

The company's marketing director, Mike Arthur, said the first they knew of the Colipa standard being promoted by Cansa was in March this year when they were invited to a meeting where Cansa presented a paper on the subject. 'We have been made to look bad, but our current certificates, based on tests conducted by Medunsa's laboratory - one of only two local laboratories that do these tests - rated our broad-spectrum ratios as five-star.' However, he admitted that the Boots standard was used, not the Colipa standard. Arthur said he had 'no knowledge' of how reliable the (Colipa)

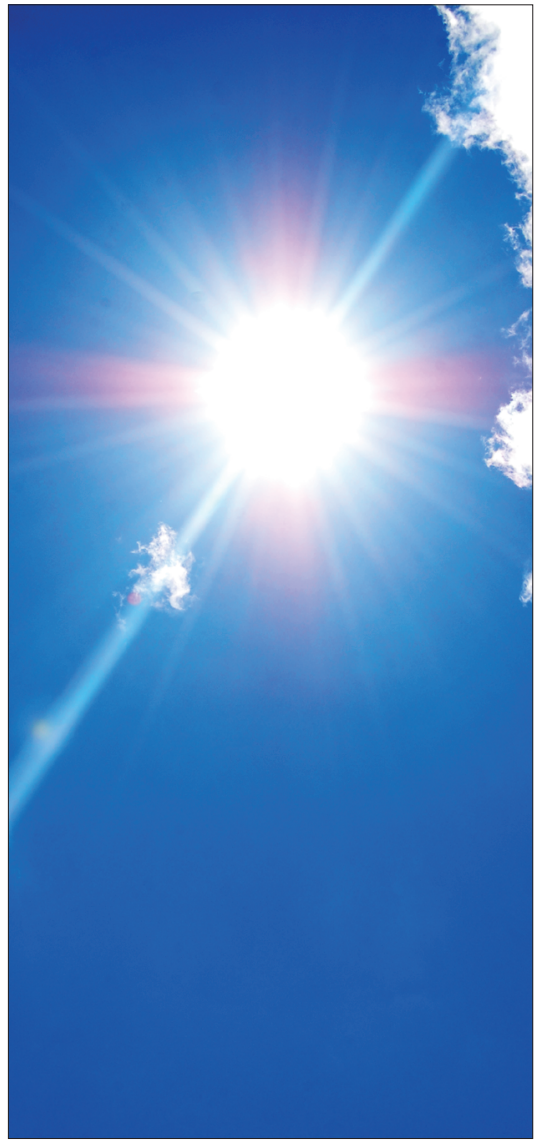

tests were, but admitted that Creighton had its work cut out to meet the March 2013 deadline set by Cansa. Products would need to be reformulated with the more expensive ingredients required to block out UVA rays available only from major multinational suppliers, and each cream would then have to be re-tested - at a cost of R40 000 per test.

\section{Dermatologists worried}

Dr Dagmar Whitaker, Cape Town dermatologist and chairman of the Melanoma Society of SA, says the Western

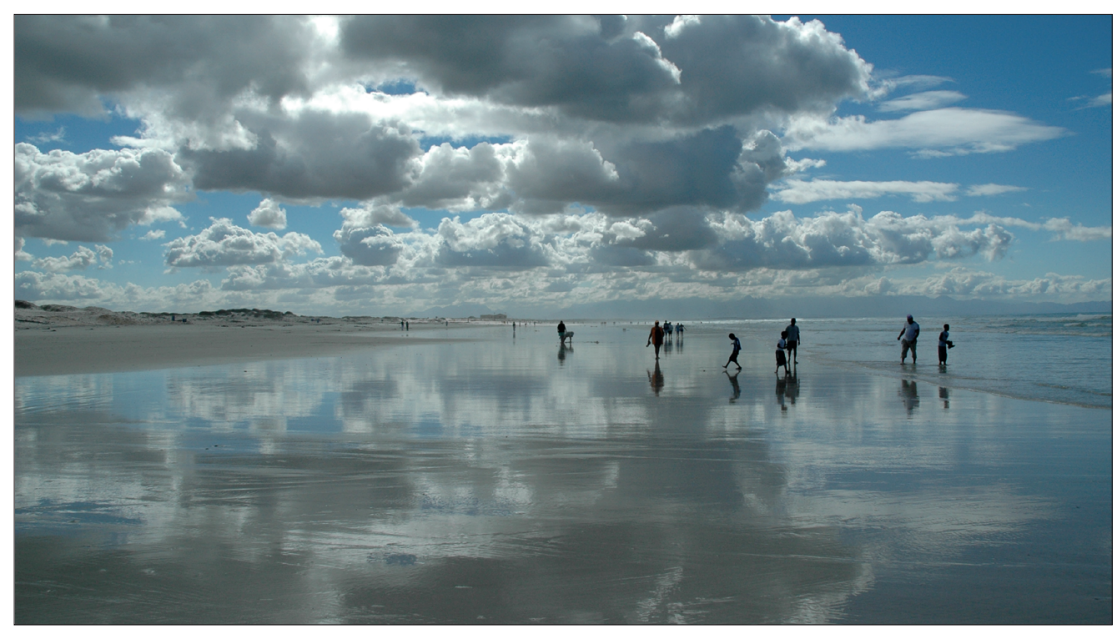

Cape has perhaps the highest incidence of malignant melanoma in the world (similar to that of Australia). 'To date we do not have accurate statistics, but the estimated figure for the Cape in 2009 was 69 new cases per year per population of 100000 Caucasians. Australia has an incidence rate of 65 per 100 000 . This translates to a prediction that 1 in 1 429 people will be diagnosed with malignant melanoma this year. Compare this with the figures for the years 1990 - 1995 and you find the incidence has trebled over the past 20 years. Clearly something needs to be done urgently to address the risk factors and reverse this trend.' Using an effective, longlasting broad-spectrum sunscreen would be one such essential precaution.

Dr Carl Albrecht, the pharmacologist/ biochemist who heads Cansa's research arm, told Izindaba that the CTFA decided this July to develop a 'better test than Colipa' It was working on specifications using the Colipa-standard testing equipment exclusive to Future Cosmetics. The CTFA committee overseeing the project was being chaired by Ms Heibrie le Roux. 'I'm told she's committed to it becoming the order of the day in South Africa, he added. In spite of three messages being left with her secretary, the second of which outlined the subject matter, Ms Le Roux did not return Izindaba's calls.

The company's marketing director, Mike Arthur, said the first they knew of the Colipa standard being promoted by Cansa was in March this year

when they were invited to a meeting where Cansa presented a paper on the subject.

Cansa intends to post each sunblock product that passes their minimumstandard Colipa test on its website as and when it becomes available next year. ${ }^{1}$ All these products will bear a newly designed Cansa logo to distinguish them from those it previously endorsed. In the meantime Cansa's advice to daily sun-lovers is to apply the highest rated broad-spectrum lotion every two hours while wearing the most protective 'activity-practical' clothing.

\section{Chris Bateman \\ chrisb@hmpg.co.za \\ 1. http://www.cansa.org.za \\ S Afr Med J 2012;102(10):778-779. DOI:10.7196/SAMJ.6252}

